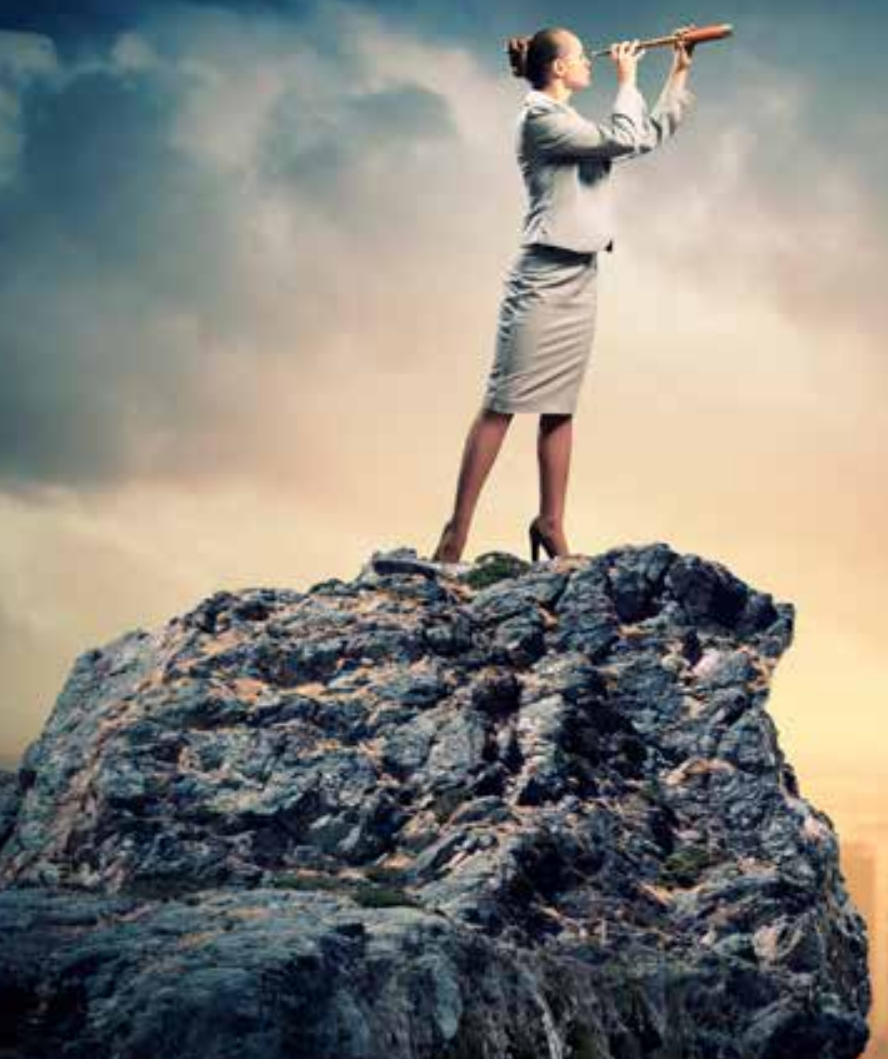

\title{
IMPLICACIONES CULTURALES Y SOCIOECONÓMICAS DE LA MUJER COMO PARTÍCIPE EN EL DESARROLLO Y FORTALECIMIENTO DE LOS SECTORES ECONÓMICOS: UN ANÁLISIS COMPARATIVO MÉXICO-CHINA
}

Cultural and socioeconomic implications of the woman as a part in the development and strengthening of economic sectors: a comparative analysis Mexico-China.

$>>$

Juan Carlos Tello Prior

Benemérita Universidad Autónoma de Puebla

carlos.tellop@correo.buap.mx 
Abstract

The entrepreneurship is presented as a current cutting edge in contemporary studies and analysis about the goals of innovation, economic growth and social development. The woman as a participant in the economy, has become a subject of research because of the implications that their active link with the formal economy sectors has within nations. Therefore, the study of empowerment of the female gender as part of trends in entrepreneurship has been the subject of worldwide reflection. In the present research the consequences, implications and indicators that this aspect has generated both in Mexico and in China, are analyzed. The objective is to compare these results according to the global entrepreneurship indicators seen from the perspective of the female gender, proposing that China brings significant progress in entrepreneurship vis-à-vis Mexico; however, the social and cultural pressure on this trend is less than that generated in the Chinese environment. Determining that entrepreneurship results for women in China and Mexico share conjectural aspects in economic, political and social matters and are analyzed based on the general conditions of entrepreneurship in each country, to the particular analyzes of the role played by women in the productive and social fabric in both nations.

\section{Keywords}

China, Mexico, women, entrepreneurship, gender equality, empowerment

\section{Resumen}

El emprendimiento empresarial se presenta como una corriente de vanguardia en los estudios y análisis contemporáneos alrededor de las metas de innovación, crecimiento económico y desarrollo social. La mujer como partícipe de la economía, se ha convertido en un tema de investigación, debido a las implicaciones que su activa vinculación con los sectores de economía formal dentro de las naciones. Por ello, el estudio de empoderamiento del género femenino como parte de las tendencias de emprendimiento empresarial ha sido motivo de reflexión a nivel mundial. En el presente artículo se analizan las consecuencias, implicaciones e indicadores que esta faceta ha generado tanto en México como en China, para ello, el objetivo se centra en comparar estos resultados de acuerdo a los indicadores globales de emprendimiento vistos desde la perspectiva del género femenino. De esta forma se propone que China conlleva un avance significativo en materia de emprendimiento frente a México, sin embargo, en México la presión social y cultural ante esta vertiente es menor que la generada en el entorno chino. Determinando que los resultados de emprendimiento empresarial para la mujer en China y México comparten aspectos coyunturales en materia económica, política y social y son analizados partiendo de las condiciones generales del emprendimiento en cada país, hasta los análisis particulares del rol que juega la mujer en el tejido productivo y social en ambas naciones.

\section{Palabras clave}

China, México, mujer, emprendedoras, innovación, equidad de género.

\section{Introducción}

El papel de la mujer en la economía ha logrado convertirse en una prioridad entre las agendas mundiales de trabajo de organismos supranacionales y multilaterales al ser una situación en donde las mujeres son discriminadas al momento de hacer negocios, y cuyas consecuencias económicas, políticas y sociales son obstáculos para la entrada exitosa de las mujeres en el desarrollo de la política y políticas públicas que las acompañan (OCDE, 2001; Asia Pacific Economic Cooperation, 2016). 
Esto, aunado a un interés creciente entre aquellos que destinan sus acciones a la construcción de la política, el sector académico y los grupos de la sociedad civil por estudiar y comprender el fenómeno del entrepreneurship, el cual nace de la preocupación por estimular el crecimiento económico y desarrollo de mercados en la economía. En donde las mujeres, desempeñan un factor preponderante dentro de la gestión y construcción del sector MIPyME1, demostrando a través de sus capacidades y habilidades una fuerte destreza para desempeñar el rol de empresaria (Weeks y Seiler, 2001).

El presente artículo contextualiza el fenómeno del emprendimiento empresarial (entrepreneurship) analizado desde la perspectiva de su gestión y desarrollo a través del empoderamiento de la mujer emprendedora, contrastando mediante la comparación las condiciones que se viven alrededor de esta variable entre México y China, tomando en consideración las implicaciones culturales y socioeconómicas que se presentan en el estímulo y desarrollo constante de esta tendencia.

Esta comparación nacida en función de algunas similitudes que se presentan entre México y China en los indicadores de trazabilidad de la vertiente emprendedora, según los estudios globales de análisis de esta variable que realizan instituciones académicas y multilaterales, partiendo de la pregunta ¿qué implicaciones culturales y socioeconómicas se generan de la inserción de la mujer como partícipe en el desarrollo y fortalecimiento de los sectores económicos en México y China?, que junto a la reflexión de ¿cuáles son los indicadores globales de emprendimiento empresarial logrados por China y México? brindan una contextualización para el seguimiento del presente estudio.

Asimismo, la respuesta hipotética ante estas interrogantes se centra en la premisa de que el estímulo del emprendimiento empresarial a través de su gestión por el género femenino, ha tenido un mayor auge y desarrollo según los indicadores globales dentro de China en comparación con México. Sin embargo, las condiciones de presión cultural y social para la inserción y éxito comercial de la mujer tiene menores limitantes en México que su contraparte China.

\section{Emprendimiento empresarial}

En la actualidad la unanimidad en la importancia de la creación de nuevas empresas es una tendencia en crecimiento, lo que genera implicaciones en el desarrollo de las economías y las metas de desarrollo económico como la generación de empleos, el estímulo como motor de la innovación, el comercio de bienes y creación de riqueza, entre otros. No obstante, un punto que incentiva la controversia es el papel del emprendedor en estas condiciones, como un protagonista en la constitución de nuevas empresas (Fuentes y Sánchez, 2010).

García y Marco (1999) señalan que al emprendedor se le ha analizado con relación a tres perfiles fundamentales: demográfico, psicológico y sociológico. Para ello, su figura como empresario ha tendido a ser analizada desde diferentes enfoques de las ciencias sociales y administrativas.

El emprendimiento empresarial es una tendencia que ha ido en crecimiento, en parte, debido a la importancia que tiene a nivel micro y macroeconómico en el fortalecimiento de los sectores empresariales para las naciones, por ende, esta variable se ha representado como una medida de análisis incremental por parte de las instituciones y gobiernos a nivel internacional (Diochon, 2004). Su importancia está relacionada con las necesidades que dentro de las naciones se acentúan, como el hecho de diversificar los mercados y aplicar el capital privado de trabajo para la generación de mercados de bienes y servicios que satisfagan en mayor medida la calidad y valor agregado esperado por los clientes o la eficiencia en el manejo de los medios de producción, lo

1 Micro, pequeñas y medianas empresas. 
cual permita el posicionamiento de los mismos en los mercados internacionales (Jones y Wadhwani, 2006).

Las economías emergentes son caracterizadas por contar con un incremento de sus mercados y expansión económica, los emprendedores juegan un papel clave dentro de este desarrollo económico ya que su tejido productivo y comercial fortalecido permite un rápido crecimiento como fuerzas alrededor del mundo (Bruton, Ahlstrom y Obloj, 2007).

El emprendedor es definido como "aquel profesional que crea un negocio con el propósito de hacerlo crecer satisfaciendo tanto las necesidades de sus clientes como las propias, a este último se le llama empresario y establece planes y estrategias buscando la innovación, nuevos productos o servicios, mercados y mejores formas de administrar" (Mendieta Díaz y Anaya Ortega, 2009: 3).

De acuerdo a Arrow (1962, citado por Pérez Hernández y Merrit Tapia, 2009) el estudio del emprendedor en la economía fue relegado en su mayoría a los análisis teóricos al privilegiar elementos de investigación como el papel que juega la información en la racionalidad para la toma de decisiones económicas, atribuyendo así una importancia micro y macroeconómica a la gestión del emprendimiento por parte de las naciones.

"Las tasas de creación de nuevas empresas varían significativamente entre diferentes países, o incluso entre diferentes regiones dentro de una misma nación. Es por ello que a menudo se argumenta que ciertas partes del mundo son más emprendedoras que otras" (Sánchez, 2008: 110). Siendo importante la reflexión acerca de sus corrientes y tendencias a fin de detectar oportunidades y amenazas entre países con competitividad económica internacional. Sin duda, la promoción de los valores y estudios en torno del emprendimiento ha tendido a realizar una serie de adaptaciones para una mayor cooperación y vinculación con los sectores sociales, productivos y académicos. En el caso de los estudios de los factores que promueven o demeritan la corriente emprendedora, la academia ha contado con un papel significativo en las naciones de Asia (incluyendo a China), esta expresión se marca en función del papel que juegan las universidades en el desarrollo del conocimiento acerca del área de emprendimiento y como caso particular, de los estudios de género vinculados con esta área del conocimiento (Wong, 2011).

La estrategia en México no dista de ser similar, en donde existe una vinculación entre las estrategias gubernamentales con el sector académico para el estímulo y capacitación de la virtud emprendedora en la sociedad. Prueba de ello es la creación de la red nacional de incubadoras de negocios, en las cuales se realiza una vinculación abierta y de cooperación entre las estrategias y políticas públicas de promoción y difusión del conocimiento con los esfuerzos de innovación y desarrollo del emprendimiento por parte de la academia a través de sus centros de investigación e incubadoras de negocios (Observatorio Nacional del Emprendedor, 2016).

El desarrollo y transformación de los países ha aceptado y adoptado al emprendimiento como una tendencia marcada de crecimiento y un factor que hace posible el generar una actividad económica vibrante (Honing, 1998).

La selección de la mujer en su actividad emprendedora, puede tener efectos netos en el incremento de los indicadores socioeconómicos, sobre todo en los flujos de crecimiento económico, por lo que la delimitación de pertenecer a la comunidad emprendedora se presenta como una actividad ambigua que debe ser enaltecida por las naciones alrededor del mundo, tal es el caso de México y China (Wei y Zhang, 2011).

Se debe considerar como la variable de emprendimiento empresarial ha sido utilizada para contrarrestar problemas de índice social y económico, la cual puede ser identificada dentro del Programa de las Naciones Unidas para el Desarrollo, allí se muestran alternativas que buscan la consolidación del emprendimiento como una forma de atenuar las condiciones de calidad de 
vida, entre ellas la disminución de la pobreza (UNDP, 2004). Así es como el emprendimiento comienza su evaluación a través de los diferentes grupos de interés (stakeholders) que lo contextualizan, uno de ellos la mujer emprendedora (Weeks y Seiler, 2001).

En palabras de Kitching (2004) el emprendimiento se presenta como una alternativa de oportunidades para las mujeres, al representar una flexibilidad a la entrada en las inversiones de capital privado, así como el dinamismo para encontrar el cambio y la innovación. Dentro de su obra Kitching cita a la UNIDO² $(1995,2001)$, en donde se estipula que estas condiciones aún no han sido optimizadas en los países en vías de desarrollo ${ }^{3}$, por lo que muchas mujeres trabajan en los sectores informales, pero su contribución a la contabilidad y economía nacional no figura de manera correcta, por lo que es indispensable estimular la habilidad de la mujer por adherirse a los esquemas productivos y el tejido social de la economía en las diferentes alternativas que los negocios y el emprendimiento ofrecen para las mismas.

Para comprender la forma en que el emprendimiento ha tenido un peso significativo en las estructuras económicas de los países de estudio de esta investigación, se debe referir a la tabla 1, la cual denota en términos de emprendimiento e innovación, un análisis comparativo previo de las directrices de esta variable y que fungirán como parteaguas para entender el papel de la mujer dentro de estas en las naciones de trabajo.

Tabla 1. Indicadores en materia de emprendimiento empresarial e innovación entre México y China

\begin{tabular}{|c|c|c|}
\hline Factor & México & China \\
\hline Ranking mundial de innovación (GIl, 2015) & 57 lugar & 29 lugar \\
\hline Calidad de la innovación (2015) & 36 lugar & 18 lugar \\
\hline Inversión del PIB en Investigación y desarrollo (I\&D) (2015) & $0.5 \%$ del PIB & $2 \%$ del PIB \\
\hline Patentes triádicas (2015) & 19 familias & 1896 familias. \\
\hline $\begin{array}{l}\text { Exportación de productos y servicios derivados a las Tecnologías de Información y Comuni- } \\
\text { cación (TIC) (2015) }\end{array}$ & 62 mil millones de dólares & 549 mil millones de dólares \\
\hline Tasas de interés para las Pymes (2015) & 9.58 & 7.51 \\
\hline Oportunidades percibidas (2014) & $31.9 \%$ & $48.9 \%$ \\
\hline Capacidades percibidas (2014) & $33 \%$ & $53.5 \%$ \\
\hline Miedo al fracaso (2014) & $39.5 \%$ & $29.6 \%$ \\
\hline Intenciones emprendedoras & $19.3 \%$ & $17.4 \%$ \\
\hline Acceso al financiamiento (2013) & 18 lugar & 3 lugar \\
\hline Cultura emprendedora (2013) & 17 lugar & 18 lugar \\
\hline Impuestos y regulación (2013) & 16 lugar & 18 lugar \\
\hline Educación y entrenamiento (2013) & 15 lugar & 18 lugar \\
\hline Esfuerzos coordinados (2013) & 2 lugar & 6 lugar \\
\hline
\end{tabular}

Fuente: Elaboración propia con datos del Global Entrepreneurship Monitor (2013), Barómetro de Emprendimiento (2013), Organización para la Cooperación y Desarrollo Económico (2014-2015) y el Global Innovation Index (2015).

De la tabla 1 se puede rescatar que las capacidades emprendedoras de ambos países se encuentran en escalas similares, con un ligero mayor posicionamiento de México en el área de emprendimiento y una alta diferencia por parte de China en contraparte con México para indicadores de innovación.

2 United Nations Industrial Development Organization.

3 El caso de China y México podrían considerarse dentro de esta premisa. 


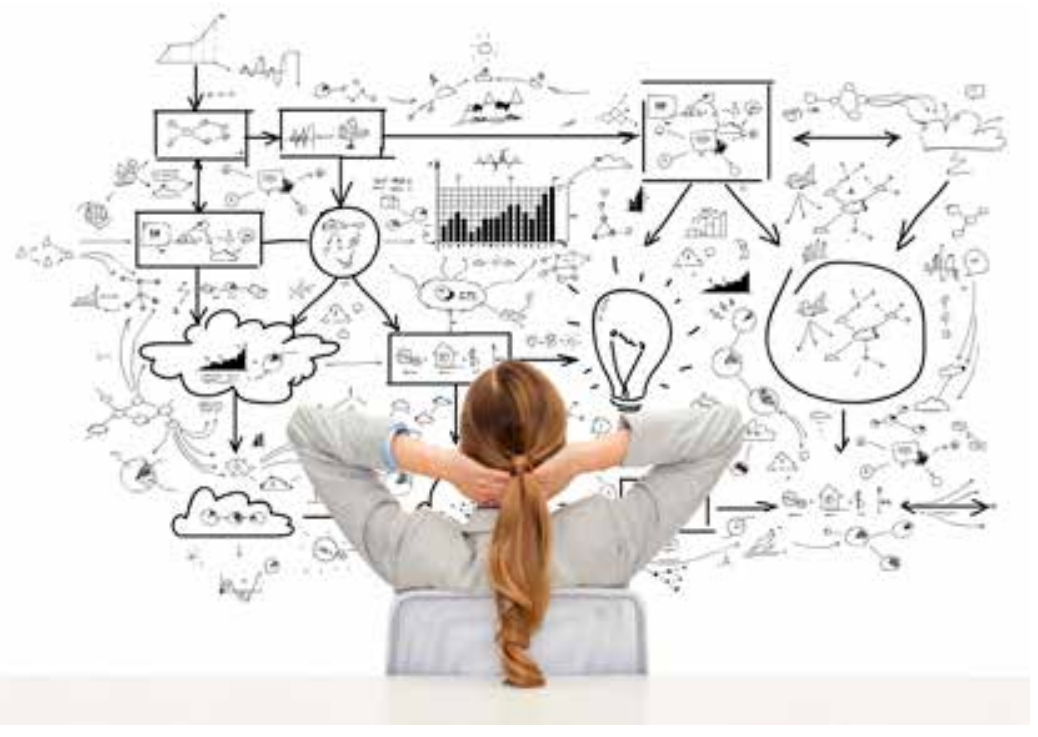

La inserción de la mujer dentro del emprendimiento empresarial

Según lo plasmado por Minitti y Arenius (2003), el desarrollo de la mujer emprendedora es una condición mundial que se ha mantenido en un desarrollo periódico y activo y que ha tenido un sinfín de vertientes para la creación y seguimiento de nuevas empresas.

A pesar de las consideraciones e importancia que tiene la mujer como población creciente de emprendedoras y su significativa contribución en las metas de innovación, empleo, creación de la riqueza y bienestar en las economías alrededor del mundo, el estudio de su comportamiento, causales y motivaciones sigue siendo un tema relativamente subestudiado (Bruin, Brush, y Welter, 2006). El papel de las mujeres emprendedoras en el estímulo y creación de empresas y negocios sobre todo de la tipología MIPyME ha sido un aspecto fundamentalmente analizado por las instituciones supranacionales, tal es el caso de la OCDE, la cual desde el año 2001 se ha pronunciado alrededor de la discriminación que en algunas naciones sufren las mujeres en la generación de negocios, lo que repercute de manera negativa en la economía, sociedad y política, con consecuencias para cada país que tienen una carencia de oportunidades e imposición de obstáculos para la inserción de las mujeres en las unidades económicas como medida de auto-empleo y la falta de políticas que disminuyan estas dificultades.

A medida que los países tienden a adoptar la democracia como un estilo político y social de trabajo, la desigualdad de género se amenora, ofreciendo una mejor atmósfera de productividad y trabajo equitativo para ambos géneros (Foster, 1996, citado en Kitching, 2004).

Para lograr posicionar la importancia de la mujer en los ámbitos laboral y directivo se debe observar el gráfico 1, el cual revela de acuerdo a indicadores de la OCDE (2010) la participación de China y México, en términos de la mujer dentro de la corriente emprendedora se representa como una variable en ascenso, logrando identificar que para México el papel de las mujeres en la fuerza laboral tiene una mayor participación con poco más de un 30\% de mujeres que trabajan, mientras que China menos de un $20 \%$, caso contrario se genera al verificar los indicadores de mujeres en puestos directivos, en donde se reflejan mayores indicadores para China con cerca del $45 \%$ de los registros de empleo.

Por su parte, de acuerdo al Programa Internacional de Evaluación Estudiantil (PISA por sus siglas en inglés), las mujeres en la República Popular China tienen mayores oportunidades de acceso a la educación de nivel superior que las mexicanas. Siendo indispensable tener en cuenta que este indicador a su vez se ve afectado por las diferencias poblacionales y demográficas que tienden a ser diez veces mayores para China y tomando en cuenta que el perfil de formación profesional de las mujeres en las ciencias sociales (literarias) es más elevado para México (ver gráfico 2). 
Gráfico 1. El papel de las mujeres en la fuerza laboral y cargos directivos en 2010
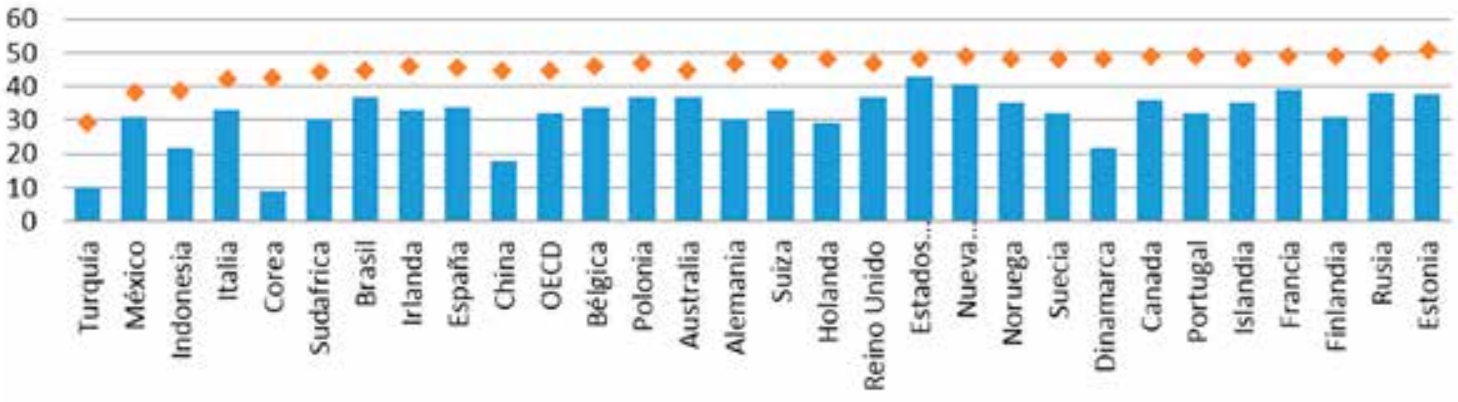

= Cargo directivo/gerencial \& Fuerza laboral

Fuente: OCDE, 2014:12

Gráfico 2. Indicadores de competencias por áreas literarias y matemáticas del programa PISA de la OCDE en 2012

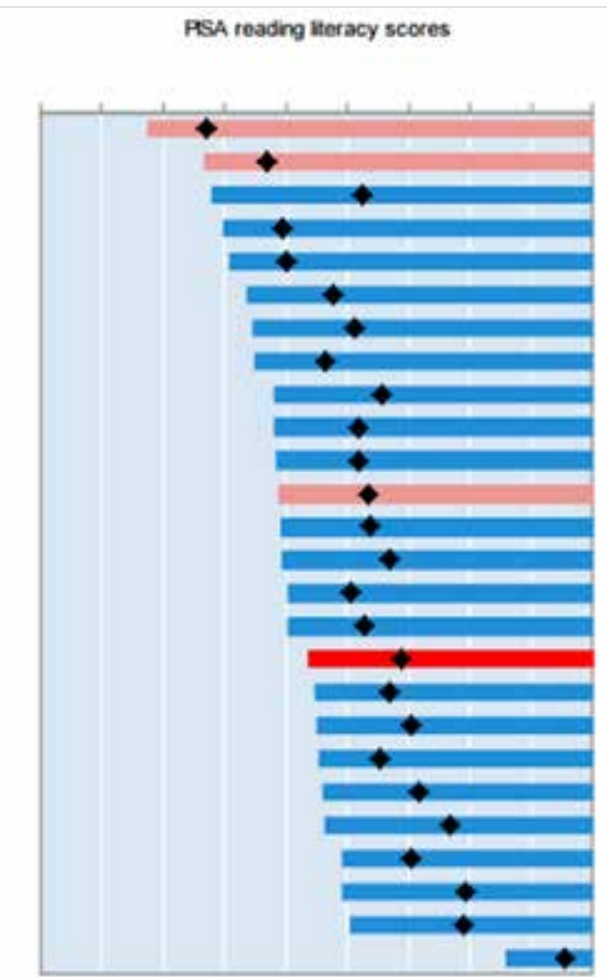

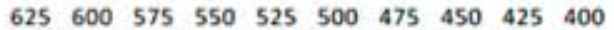

Girls $\bullet$ Boys
Shanghai-China
Hong Kong-China
Finland
Japan
Korea
Canada
Poland
Ireland
Germany
New Zealand
Australia
Macao-China
Switzerland
France
Netherlands
Belgium
OECD average
United States
Czech Republic
United Kingdom
Italy
Sweden
Spain
Greece
Turkey
Mexico

PSA mathermatics scores

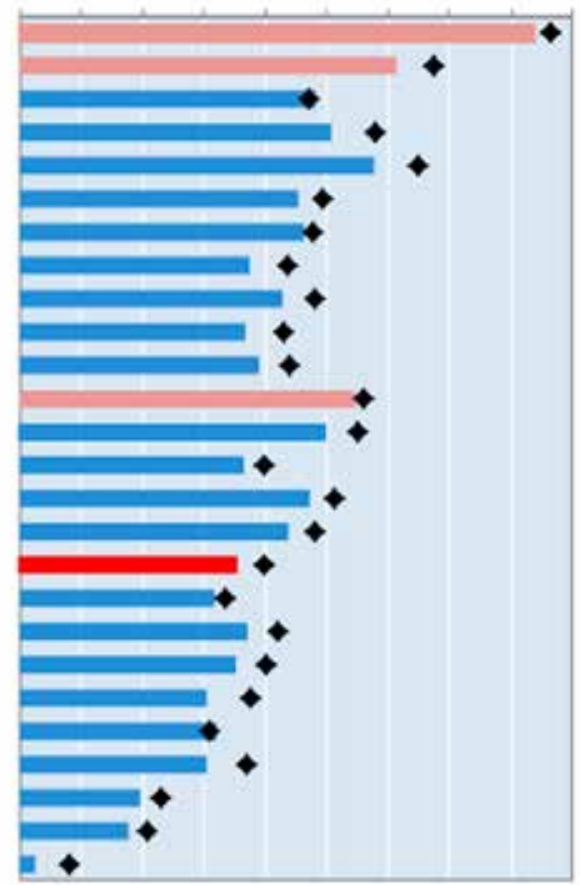

$\begin{array}{llllllllll}400 & 425 & 450 & 475 & 500 & 525 & 550 & 575 & 600 & 625\end{array}$

Fuente: OCDE, 2014:13. 
Según el Banco Mundial (2010), la participación de las mujeres en la economía global es una situación con un incremento parcial, en la que los tabúes y limitantes sociales y culturales son erradicadas cada vez con mayor actividad por parte de la sociedad y las propuestas gubernamentales en las diversas regiones del mundo.

La participación de las mujeres en la economía se ha visto alentada a través del estímulo y subsidios propuestos por las diversas instituciones como medida para complemento al trabajo. Los sistemas suelen responder ante estas circunstancias y los programas gubernamentales continúan en una evolución para mantener un buen desempeño económico, que se vea a su vez conjuntado con acciones de seguridad social y calidad de vida para la población, teniendo como punto relevante el papel de la mujer en este acometido (Hekerson y Sanandaji, 2011).

\section{La mujer y el emprendimiento empresarial en China y México}

En el ámbito de la comparación entre naciones y una variable de estudio como la inserción de la mujer dentro del ámbito del emprendimiento empresarial, un punto crítico al respecto es identificar los logros que se han generado en torno a esta posición, así como la identificación de los perfiles que demarcan estas actividades y corrientes de vanguardia en el mundo y las intenciones públicas y sociales que la estimulan.

El entorno social o cultural en el cual se desenvuelven las diferentes naciones implica cambios en la estructura de la cultura emprendedora y más aún en el aspecto de desarrollo de negocios por parte del género femenino (Weeks y Seiler, 2001).

El papel de la mujer emprendedora en el mundo es una condición innegable, no estando México y la República Popular China ajenos a estas condiciones. En el caso de la segunda, estas particularidades se ven representadas tanto por su legado histórico comunista, como la idiosincrasia peculiar que este país representa (Tambunan, 2009).

Para el caso de México los indicadores de autoempleo de las mujeres se han incrementado de 2000 al 2012, sin embargo, este crecimiento ha sido gradual, al no identificarse un incremento exponencial de la participación de las mujeres dentro de la corriente emprendedora. Lo que es destacable es el ímpetu de la mujer por adherirse a las estructuras sociales y económicas mediante sus intenciones de creación de iniciativas de inversión de capital privado (véase gráfico 3).

Gráfico 3. Incremento del auto-empleo por parte de las mujeres, 2000-2012

$=2000=2005=2012$

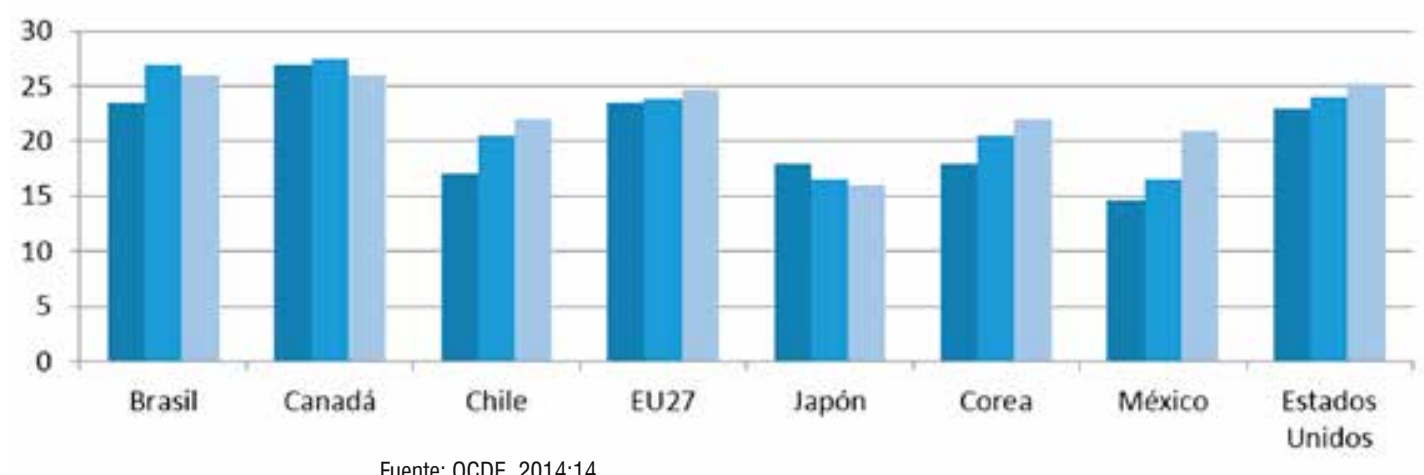

Fuente: OCDE, 2014:14. 
De acuerdo a la OCDE (2014), China se mantiene en los primeros niveles de importancia para la corriente emprendedora por parte de las mujeres, quienes representan un interés en el auto-empleo de manera creciente apenas superado por algunos puntos porcentuales por Brasil y Turquía. Estas condiciones denotan una capacidad de inserción adecuada de las mujeres emprendedoras chinas en las metas económicas que figuran en la corriente del desarrollo de nuevas empresas y negocios dentro de su país (véase gráfico 4).

Gráfico 4. Preferencias del auto empleo por género en 2012

a Mujeres $\diamond$ Hombres

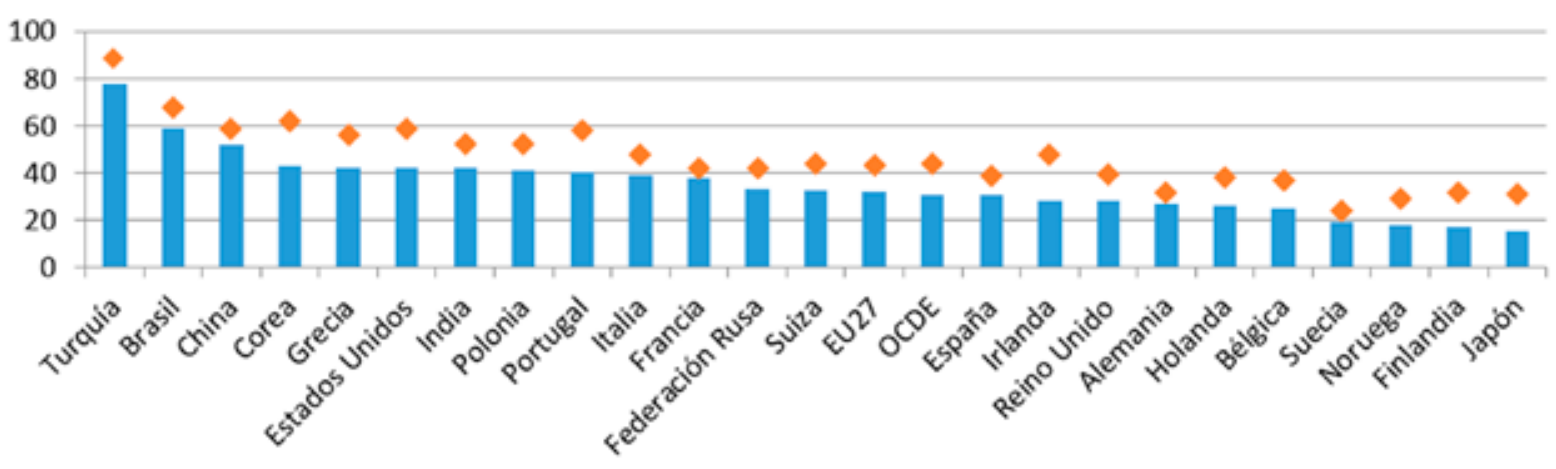

Fuente: OCDE, 2014.

El emprendimiento es una corriente que en México se ha suscitado de manera contemporánea a pesar de que las políticas públicas de hace algunas décadas se han inclinado hacia el fortalecimiento de los sectores empresariales. Tal es el caso de la visión actual, la cual ha permitido un mayor estímulo de esta tendencia económica, pues para el 2003 la representatividad entre la actividad emprendedora de hombres y mujeres se encontraba en crecimiento por parte del género femenino, mientras que en China se encontraba con indicadores homogéneos a los generados por México (véase gráfico 5).

Gráfico 5. Actividad emprendedora por género y país en 2009.

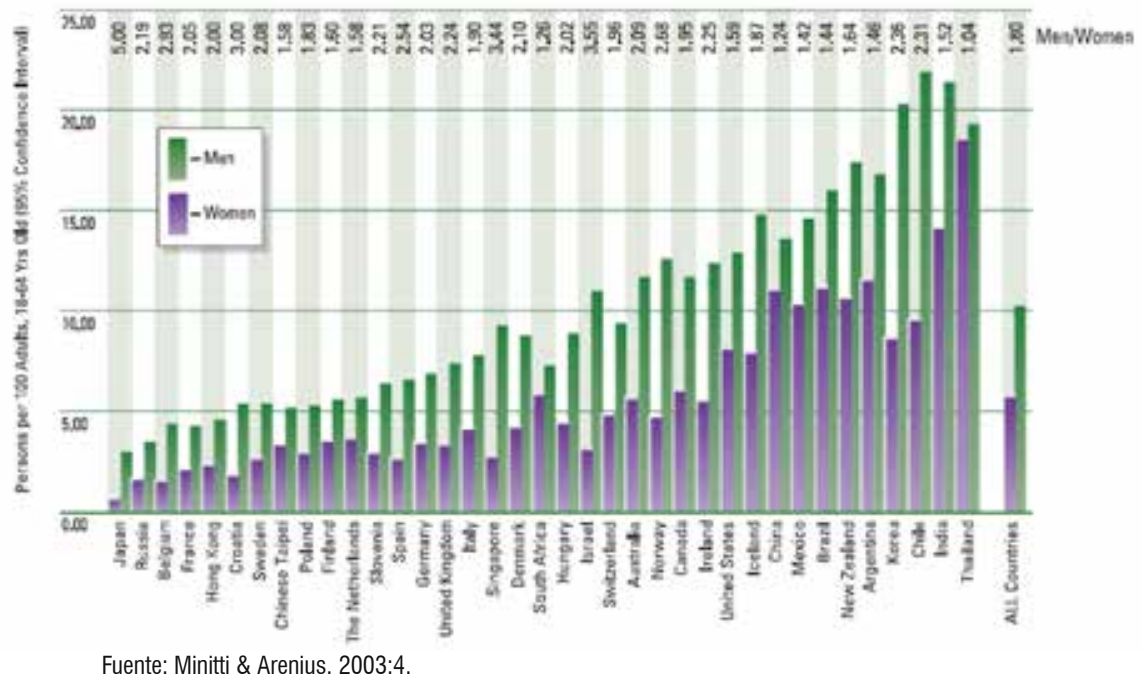

Fuente: Minitti \& Arenius, 2003:4. 
Al analizar a México y China, el estudio comparativo ha permitido delimitar cuales son las implicaciones que la mujer emprendedora ha tenido dentro del contexto del emprendimiento. En primera instancia, se puede afirmar que la intervención de la mujer en las variables económicas ha sido una predilección asequible por sus beneficios en una gran cantidad de naciones (Sverian y Nedelea, 2014).

Las motivaciones de emprendimiento de las mujeres son una condición que se deriva de aspectos sociales, espirituales o de identificación con sus vidas, las mujeres tienen en común la motivación a la autorrealización y el deseo de mantener el control de su destino, por lo que la mujer emprendedora mantendrá sus necesidades de generar beneficio económico al trabajar para ella misma y con ello contribuir en otros grupos de interés (Halladay y Thomas, 2002). En el preámbulo cultural las limitantes a un flujo adecuado de la participación de la mujer de la economía se ve inmersa en una serie de legados históricos respecto a la inequidad de género, favoreciendo al género masculino; en el caso de México esta condición se ha denominado "machismo" (Garduño, 2012), mientras que para el caso de la República Popular China está de la mano de las estructuras sociales y los aspectos generacionales que se acompañan de los prefijos sociales y culturales alrededor de la mujer (Hendrishke y $L i, 2012$ ), escenario que afortunadamente se encuentra en proceso de recesión (Bruin, Brush y Welter, 2006).

\section{Perfil de la emprendedora mexicana y china}

De acuerdo a Plant (2009), el estudio del emprendimiento y las intenciones emprendedoras es un tema que ha recobrado importancia en múltiples investigaciones y desde diferentes perspectivas en donde se destaca el estudio de factores como: personalidad, habilidades cognitivas, desarrollo de antecedentes emprendedores, comportamiento, carrera emprendedora e indicadores de auto empleo. Según estudios presentados por Wong (1992, citado en Plant, 2009) los valores propios de las relaciones personales en especial de los vínculos familiares, se convierte en un aspecto trascendental al entender las estructuras organizacionales chinas y en particular su formación y desarrollo de actividades emprendedoras. Por ello, se convierte en importante un análisis de perfiles emprendedores analizados mediante criterios específicos como la igualdad de derechos, miedo al emprendimiento, oportunidades, entre otras variables (Tabla 2).

En la tabla se puede visualizar que las particularidades en el perfil de la emprendedora china y mexicana tienen aspectos en común, esto en parte por las condiciones culturales de estas áreas, que han mantenido al margen a la mujer emprendedora de una participación fluida en los negocios y fuerza laboral, situación que se representa en atención por parte de los grupos de interés político y social que buscan resarcir estas condiciones y lograr una adecuada igualdad de género entre las capacidades de insertarse en las iniciativas de inversión de capital privado por parte de las mujeres. 
Tabla 2. Análisis del perfil cultural y sociológico de la emprendedora china y mexicana.

\begin{tabular}{|c|c|c|}
\hline Criterio & Emprendedora China & Emprendedora mexicana \\
\hline Igualdad de derechos & $\begin{array}{l}\text { Instituido dentro de la legislación de la República } \\
\text { Popular China. }\end{array}$ & $\begin{array}{c}\text { De acuerdo a la Constitución Política de los } \\
\text { Estados Unidos Mexicanos. }\end{array}$ \\
\hline Intenciones de emprendimiento & Apoyar a la economía doméstica y familiar. & $\begin{array}{l}\text { Obtener nuevas fuentes de ingresos para solven- } \\
\text { cia familiar o personal. }\end{array}$ \\
\hline Puestos gerenciales & $\begin{array}{l}\text { Subrepresentados por las mujeres de manera } \\
\text { gradual y ascendente, con una inclinación hacia } \\
\text { el género masculino, relacionado con el grado de } \\
\text { estudios y formación. }\end{array}$ & $\begin{array}{l}\text { Ostentados en su mayoría por el género mascu- } \\
\text { lino con una mayor presencia de la mujer en la } \\
\text { fuerza laboral. }\end{array}$ \\
\hline $\begin{array}{l}\text { Tipología empresarial en la que se } \\
\text { concentran sus esfuerzos }\end{array}$ & $\begin{array}{l}\text { Los esfuerzos de la mujer emprendedora china, } \\
\text { se presentan con prioridad en empresas micro y } \\
\text { pequeñas. }\end{array}$ & $\begin{array}{l}\text { Las características de las iniciativas empresaria- } \\
\text { les mexicanas se concentran en las empresas de } \\
\text { tipo MIPyME }\end{array}$ \\
\hline Razones para emprender & $\begin{array}{l}\text { Ligados a la conducta familiar y como estrategia } \\
\text { de vida, aunados a una cosmovisión cultural y } \\
\text { legado familiar. }\end{array}$ & $\begin{array}{l}\text { Medio de superación y desarrollo, tanto familiar } \\
\text { como profesional. }\end{array}$ \\
\hline $\begin{array}{l}\text { Motivaciones para mantenerse en la } \\
\text { corriente emprendedora }\end{array}$ & Superación, economía, poder y oportunidades. & $\begin{array}{l}\text { Necesidad, crecimiento, superación y autorrea- } \\
\text { lización. }\end{array}$ \\
\hline Acciones en conjunto & $\begin{array}{l}\text { La actividad emprendedora tiende a realizarse de } \\
\text { manera personal. }\end{array}$ & $\begin{array}{l}\text { La actividad emprendedora se realiza de manera } \\
\text { grupal en su mayoría. }\end{array}$ \\
\hline Miedo al emprendimiento & $\begin{array}{l}\text { Las mujeres emprendedoras chinas presentan un } \\
\text { miedo gradual al fracaso debido a las implicacio- } \\
\text { nes sociales que esta condición refleja. }\end{array}$ & $\begin{array}{l}\text { Temeraria ante los retos que la creación de nego- } \\
\text { cios y gestión de los mismos presupone. }\end{array}$ \\
\hline En general & $\begin{array}{c}\text { Las mujeres en China tienden a contar con capa- } \\
\text { cidades de percepción ante las oportunidades, } \\
\text { aunque no en los mejores niveles de la región. Su } \\
\text { adhesión en la tecnología e innovación es parcial } \\
\text { y en la internacionalización de sus empresas } \\
\text { menor. }\end{array}$ & $\begin{array}{l}\text { Las intenciones emprendedoras de las mexicanas } \\
\text { se comportan alrededor de expectativas que } \\
\text { van desde los sectores de servicios hasta en un } \\
\text { menor término la innovación, como parte de sus } \\
\text { estrategias y empresas creadas. }\end{array}$ \\
\hline
\end{tabular}

Fuente: Elaboración propia con información de GEDI (2016), GEM (2014), Chu, P. (2000), Garduño (2012), Plant (2009), Rodríguez y Fuentes (2013).

Según la UNCTAD (2010) la representatividad de las mujeres en la economía es una tendencia creciente a nivel mundial, sin embargo, esto genera la siguiente cuestión: ¿Qué está pasando en México y China en términos institucionales y de las políticas que acompañan a la variable de emprendimiento sobre la mujer?

Para responder esta pregunta, se analizarán las políticas públicas y estrategias nacionales para el desarrollo de esta variable. Por ejemplo, en México se cuenta con una mayor intención gubernamental por lograr, gracias a políticas públicas de subsidios y subvenciones, adherir a la mujer en el tejido productivo, gracias a programas como Mujer Emprendedora del Instituto Nacional del Emprendedor (INADEM) que busca el desarrollo y consolidación de micro, pequeñas y medianas empresas lideradas por mujeres, con acceso a financiamiento preferencial y a herramientas de desarrollo empresarial (INADEM, 2016), o Mujer PyME del Instituto Nacional de la Mujer (INMUJER) que a través de financiamiento de primer nivel estimulan y fomentan la virtud emprendedora dentro de las mujeres (INMUJER, 2016).

Sin embargo en China, las intenciones institucionales y gubernamentales se inclinan a un mayor enaltecimiento de la fortificación de esta actividad mediante estrategias de innovación y desarrollo tecnológico (cuestiones que 
se pueden identificar en el Female Entrepreneurship Index, FEI), teniendo en cuenta por parte del Ministerio de Comercio de la República Popular China la facilitación de mecanismos institucionales que estimulen la creación y el ambiente para una sana competencia, reformas sistemáticas para la profundización en los negocios, el fortalecimiento de la propiedad intelectual, y la adopción de medidas para involucrar nuevos grupos de interés en la economía (en este caso las mujeres).

A su vez, se determinan políticas financieras que permitan contribuir con financiamiento y apoyo al fondeo de las iniciativas de capital privado, en búsqueda de nuevos sectores e innovación así como la facilitación de la inversión (People's Republic of China State Council, 2016).

Se puede identificar como los esfuerzos reflejados en términos de políticas públicas por México atienden a una mayor relevancia en la institución de planes de mejora, mientras que en el caso de China se concentran en las capacidades y estímulo del talento de la mujer emprendedora como resultado de una serie de mecanismos de fomento de esta variable desde una perspectiva diversificada, que está en función de criterios propios del empoderamiento y la búsqueda de la innovación.

De acuerdo a los indicadores de la OCDE (2014) y del Global Entrepreneurship Monitor (2013) México se encuentra entre los países más emprendedores a nivel mundial, parte de ello, estimulado gracias a las intenciones que han generado las mujeres como parte especial en el desarrollo de esta variable en el contexto (GEDI, 2016), lo que lleva a pensar que el preámbulo para la mujer emprendedora mexicana se encuentra en una fase evolutiva y de mejora continua.

Esta circunstancia se ha convertido en evolutiva, si se analizan los indicadores de autoempleo presentados por Fairlile y Woodroof (2007), se puede identificar como la tasa de auto empleo para el año 2000 era de un $22.1 \%$ para las industrias no agroalimentarias y de $25.8 \%$ en todas las industrias en el género masculino, mientras que para el género femenino esta condición presentaba indicadores de $16.4 \%$ en no agroalimentarias y $17 \%$ en todas las industrias, lo que demarca una mayor participación emprendedora del género masculino, hasta la fecha. Esta situación se encuentra en proceso de equilibrio, sin embargo, ha sido gradual a través del tiempo (Minitti y Arenius, 2003).

Según los estatutos de la constitución de la República Popular China, los derechos de igualdad de la mujer son un requerimiento de carácter obligatorio, misma realidad que se refleja para México una igualdad de condiciones para el género femenino, lo que obliga a pensar que las oportunidades de estimular la creación y manejo de negocios y de participar en las actividades económicas es un derecho universal para las mismas.

Según los datos del Female Entrepreneurship Index (2015) desarrollado por $\mathrm{GEDI}^{4}$, la competitividad del emprendimiento liderado por mujeres en México se encuentra en el ranking mundial en el lugar número 41 con un $42.8 \%$, mientras que para el caso de China la posición mundial se ubica en el número 48 con el $38.3 \%$, lo que proyecta una mayor participación de las instituciones y sociedad femenina en México ante los retos del emprendimiento para este indicador.

Es de destacar dentro de este estudio, que en términos del posicionamiento de la mujer emprendedora México y China aún demuestran un rezago de las oportunidades de emprendimiento frente al género masculino, lo cual se puede contrastar al analizar de forma comparativa el Global Index propuesto por GEDI frente al Female Index de este mismo instituto, teniendo resultados más favorables para ambas naciones el primero.

4 Global Entrepreneurship and Development Institute. 
Dentro de este mismo reporte se analizan los criterios de trabajo en función de las mujeres emprendedoras mediante unas variables prioritarias, identificadas gracias a 15 puntos los cuales se presentan en la tabla 3, y que será el referente para el análisis de histogramas de los gráficos 6 y 7.

Tabla 3. Indicadores de desempeño emprendedor de acuerdo al Female Entrepreneurship Index 2015

\begin{tabular}{|c|c|c|c|}
\hline Pilar / Indicador & Pilar / Indicador & Pilar / Indicador & Pilar / Indicador \\
\hline $\begin{array}{l}1 \text { Reconocimiento de oportunidades } \\
1 \text { Igualdad de derechos } \\
1 \text { Tamaño de mercado } \\
2 \text { Percepción de habilidades } \\
2 \text { Educación secundaria } \\
3 \text { Deseos de empezar } \\
3 \text { Riesgo de negocios }\end{array}$ & $\begin{array}{l}4 \text { Conocimiento de un emprendedor } \\
4 \text { Internet y Redes } \\
5 \text { Estatus Ejecutivo } \\
5 \text { Acceso a guarderías } \\
6 \text { Oportunidades de Negocio } \\
6 \text { Mejor libertad y movimiento } \\
7 \text { Sector de la tecnología } \\
7 \text { Absorción de la tecnología }\end{array}$ & $\begin{array}{l}8 \text { Dueños altamente escolarizados } \\
8 \text { Apoyo y capacitación para MIPyME } \\
9 \text { Innovación } \\
9 \text { Mercados monopolizados } \\
10 \text { Proporción de emprendimiento } \\
10 \text { Paridad de la fuera laboral } \\
11 \text { Nuevos productos } \\
11 \text { Transferencia de tecnología }\end{array}$ & $\begin{array}{l}12 \text { Nueva tecnología } \\
12 \text { Investigación y Desarrollo } \\
13 \text { Empresas Gacelas } \\
13 \text { Liderazgo femenino } \\
14 \text { Focalización de expertos } \\
14 \text { Globalización } \\
15 \text { Financiamiento de primer nivel } \\
15 \text { Financiamiento de tercer nivel }\end{array}$ \\
\hline
\end{tabular}

Fuente: Elaboración propia con datos del Female Entrepreneurship Index del GEDI (2015).

De acuerdo con estos indicadores, en los gráficos 6 y 7 se presentarán los resultados globales logrados tanto por México como China, lo que permite realizar la comparación de premisas ante la vertiente de emprendimiento por ambas naciones (vista desde la perspectiva del género femenino). Al analizar los resultados logrados por China, la variable con los indicadores más favorables es el acceso al financiamiento de tercer piso (banca comercial privada), mientras que aquella que representa mayores fuentes de oportunidad es el manejo del sector de la tecnología.

Para el caso de México la proporción o tasa de emprendimiento es el factor de mayor ponderación entre los analizados, siendo esta una variable significativa al tener mayor presencia internacional en el emprendimiento que su contraparte asiática. Por otro lado, el acceso a fuentes de finaciamiento de primer nivel, es una alternativa a la baja con el resultado más bajo de los analizados. Sin embargo, este no es el caso de China, pues éste último mantiene los indicadores globales más significativos.

De manera general se puede visualizar resultados similares entre ambos países, lo que ha valido a México de mejores indicadores en términos de emprendimiento, pero, en efectos prácticos y de implicaciones económicas y culturales de la mujer en la economía y sociedad, de acuerdo a los argumentos del GEDI (2016) y complementado con los criterios de Nedelea y lacob (2014) China se ha representado como un gran referente en la inclusión de la mujer en la economía valida de los beneficios que ante su población y sociedad la misma representa.

Gráfico 6. Indicadores globales de emprendimiento del género femenino para China

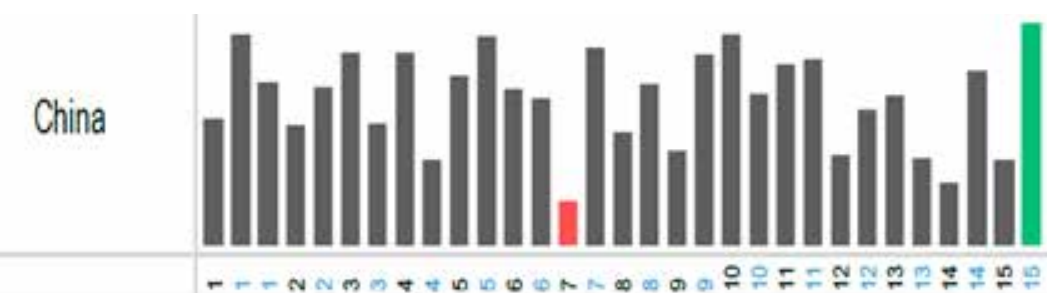

Fuente: GEDI, 20165

5 Cada indicador de estudio analizado por parte del GEDI a través de diversas instituciones como el Banco Mundial, Global Entrepreneurship Monitor, Organización Internacional del Trabajo, entre otras. 
Gráfico 7. Indicadores globales de emprendimiento del género femenino para México

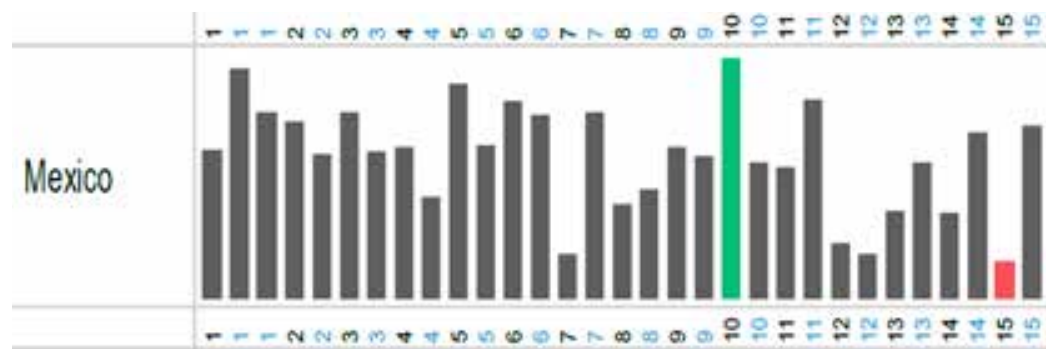

Fuente: GEDI, 20165.

La comparación de actividades emprendedoras entre géneros ha sido una tarea que han asumido diversas instituciones dedicadas a la medición de esta tendencia, el Global Entrepreneurship Monitor, en su edición 2014, evalúa en términos de la mujer emprendedora los criterios del emprendimiento, haciendo una comparativa de géneros, de donde se puede destacar que el porcentaje de adultos buscando el lanzamiento de una iniciativa empresarial es similar en China y México, destacando que para este último, existe un mejor indicador por lo que se puede decir que existe una mayor intención por parte de la mujer emprendedora mexicana (véase gráfico 8).

Gráfico 8. Porcentaje de adultos intentando hacer negocios en China y México en 2014

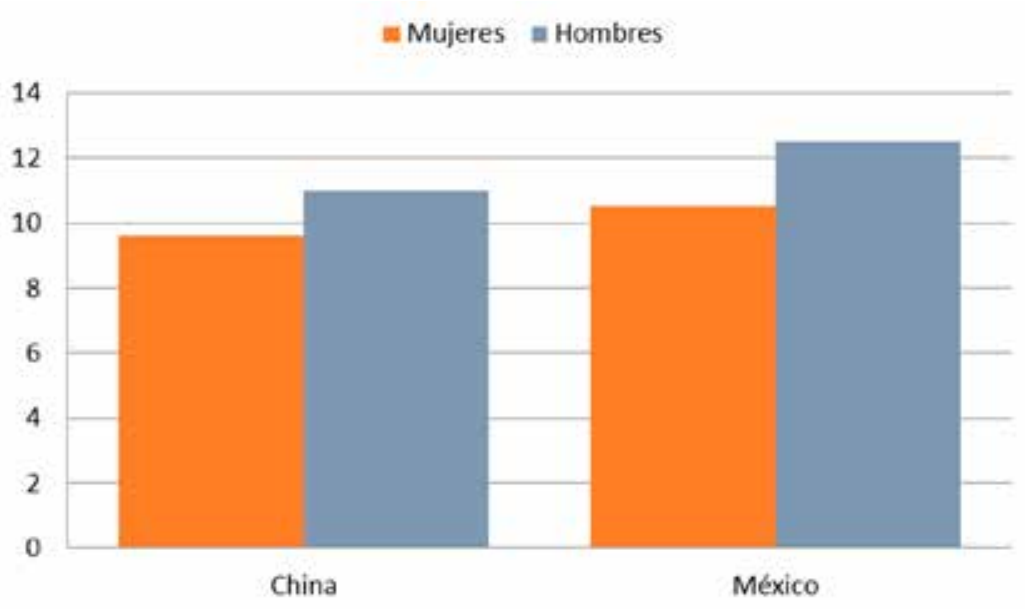

Fuente: Elaboración con datos del GEM, 2014.

Por otro lado, al analizar la tasa de intención emprendedora, se reflejan para el caso de China datos que deparan un 15\%, mientras que en México se encuentra por encima del $20 \%$, lo que muestra como la decisión de formar negocios por parte de los mexicanos es amplia frente a esta nación (véase gráfico 9). En la propiedad de empresas ya establecidas, China tiene una mayor proporción de indicadores por encima del 10\% en la medición, mientras que México se encuentra apenas por encima del $6 \%$, lo que implica que las mujeres en este primer país, contribuyen de manera más abierta en la economía y por ende, hay una mayor implicación social y cultural de las mismas como parte del tejido social y productivo de esta nación (véase gráfico 10). Mientras que en el Gráfico 11 se puede analizar que el nivel educativo de la mujer emprendedora China se encuentra por encima de los registros logrados por las mexicanas. 
Gráfico 9. Tasa de intención emprendedora China-México

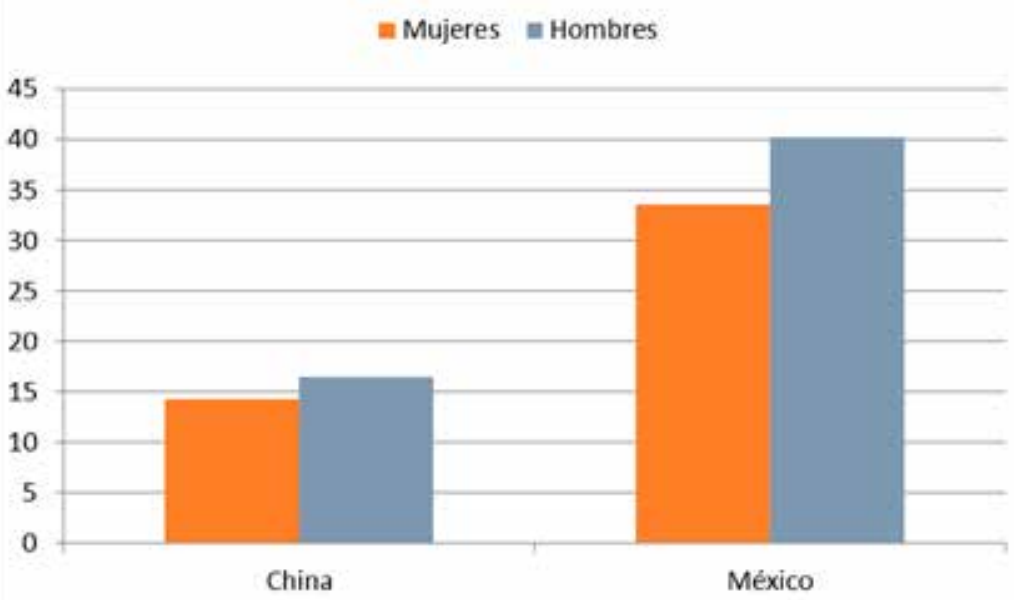

Fuente: Elaboración con datos del GEM, 2014.

Gráfico 10. Propiedad de empresas ya establecidas por género México-China

= Mujeres $=$ Hombres

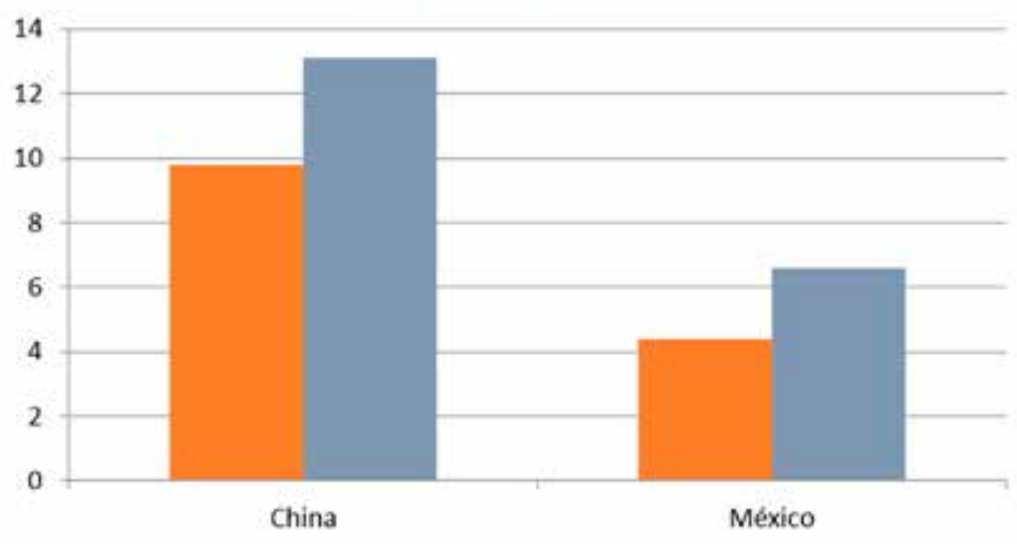

Fuente: Elaboración con datos del GEM, 2014.

Dentro del gráfico 12, se visualiza como en México la población, en especial las mujeres, se sienten preparadas y con capacidad de iniciar actividades empresariales, mientras que para China este factor se presenta muy por debajo de los porcentajes logrados por México, lo que denota dentro del perfil emprendedor la aceptación al riesgo (regularmente no planificado) por parte de las mujeres emprendedoras mexicanas. 
Gráfico 11. Porcentaje de emprendedores con nivel de educación superior México-China

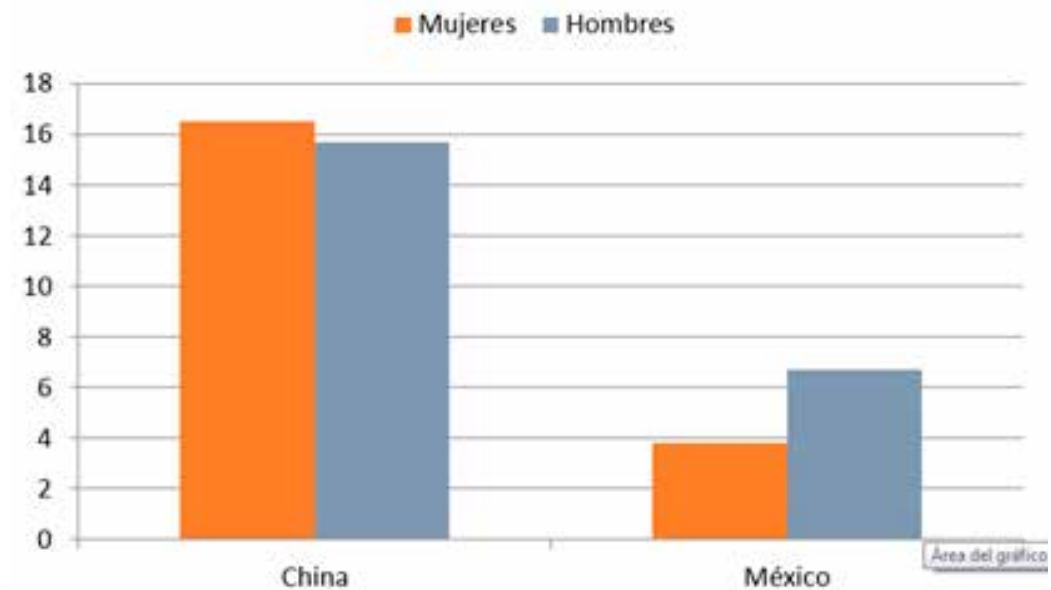

Fuente: Elaboración con datos del GEM, 2014.

Gráfico 12. Porcentaje de pobladores que creen tener habilidades emprendedoras en México y China (2014)

mujeres $=$ Hombres

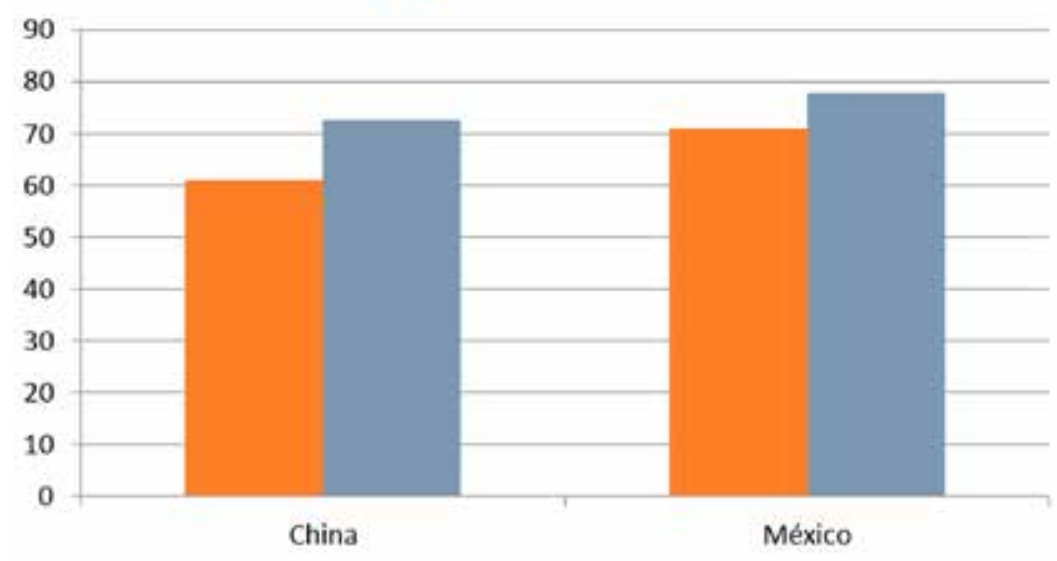

Fuente: Elaboración con datos del GEM, 2014.

A su vez en el gráfico 13 se puede observar como el miedo al fracaso emprendedor es un defecto del cual carecen con mayor aseveración las mujeres chinas, mientras que las mexicanas se reflejan inseguras de sus capacidades al iniciar un negocio con porcentajes superiores al $30 \%$. 
Gráfico 13. Miedo al fracaso a emprender, México-China (2014)

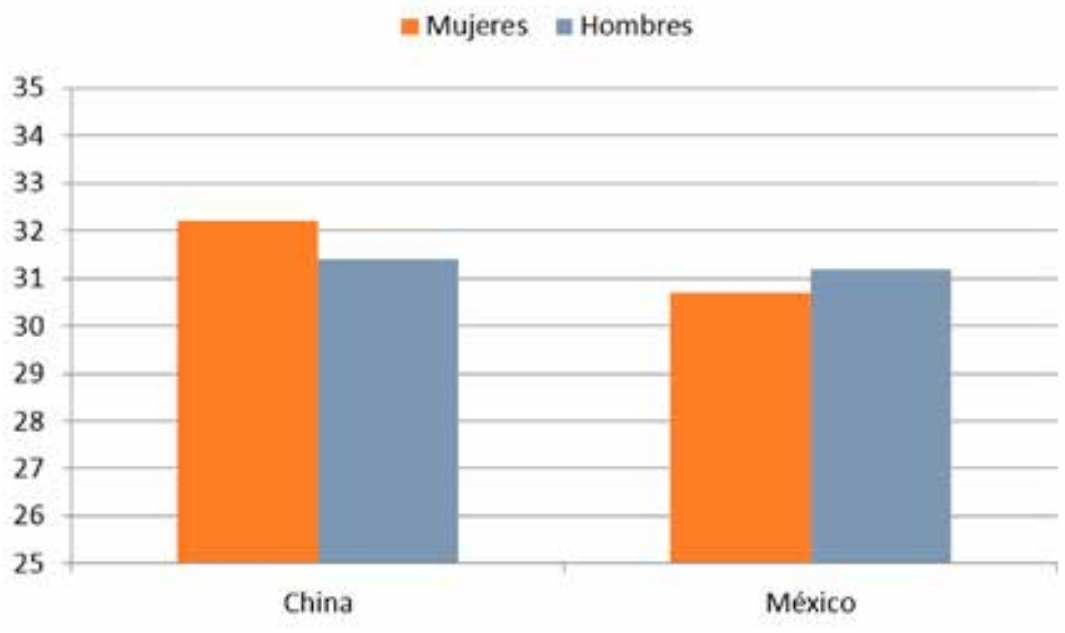

Fuente: Elaboración propia con datos del GEM, 2014.

Para comprender el papel y evolución comparativo de los indicadores de China y México en función de los factores de la mujer emprendedora en sus escenarios económicos, es necesario remontarse a las publicaciones y resultados planteados por los organismos evaluadores de estas condiciones en el mundo, en el Female Entrepreneurship Index, desarrollado por el Global Entrepreneurship Development Index (GEDI, 2016), en donde se pueden observar los resultados de esta corriente propulsada por la inserción de mujeres en las unidades económicas y como líderes en el proceso de desarrollo de negocios. En el caso de Asia, así como en otras partes del planeta, el desarrollo de la mujer emprendedora ha tenido un potencial de crecimiento enorme y su empoderamiento ha permitido una transformación ideológica, cultural y social en la región. Sin embargo, en zonas en las que el desarrollo económico todavía no se ve reflejado por el Producto Interno Bruto (PIB) per Cápita y el grado de industrialización, esta variable tenderá a ser baja o menor y permanecerá relegada (Tambunan, 2009), siendo estas premisas aplicables en algunos puntos geográficos de la República Popular China.

Para China, el fenómeno del emprendimiento y creación de MIPyME ha sido una tendencia favorable, debido a los resultados que esto ha tenido en el estímulo del consumo interno ${ }^{6}$. Históricamente, esto se presenta como un área de oportunidad relativamente nueva para los pobladores de China, al liberalizarse la inversión de capital privado con las reformas suscitadas en los años de 1980 y su enmienda en la Constitución para el año de 1988, lo que inicia con un período de fuentes de ingreso y trabajo tanto para el género femenino como masculino en esta nación (Kitching y Woldie, 2004), permitiendo así que las mujeres comenzaran un camino de apertura y destrucción de barreras ideológicas, logrando mezclarse de manera gradual en la vida económica y laboral dentro del territorio geográfico de China, y ampliando así la gama de posibilidades para las metas y objetivos económicos y sociales de este estado. A esto hay que sumar los preceptos identificados por Hendrishke y Li (2012) sostienten gracias a los argumentos de Morris et al (2006), que aquellas mujeres que son "jaladas" al emprendimiento tenderán a contar con una mejor

6 Realidad que aqueja en los indicadores macroeconómicos globales de actualidad.

7 Concepto que parte de la teoría de pull/push del emprendimiento empresarial que determina que las iniciativas emprendedoras se comportan a través de un estímulo "jalar" o una necesidad "empujar" para su desarrollo. 
orientación sobre las estrategias y comportamiento a llevar a cabo para el crecimiento de su empresa, mientras que Hughes (2003) indica que aquellas mujeres que son "empujadas"7 hacia el emprendimiento de negocios por diversas cincurstancias o necesidades tendrán una menor respuesta ante este entorno empresarial.

La participación de la mujer mexicana en la economía al igual que en China ha generado una serie de controversias. Autores como Garduño (2012) detectan disparidades regionales que este género sufre en el país, especialmente en factores como la educación, la industrialización, la urbanización, entre otros, aspectos tácitos al estímulo de la corriente económica de adhesión de las mujeres en los tejidos productivos como emprendedoras mediante la gestión de iniciativas empresariales de capital privado.

"Para México el papel de la mujer como partícipe en la economía, se ha incrementado de un 32.9 \% para el año de 1987 a 41\% a finales del 2010, lo que refleja en el contexto de la economía mexicana una tendencia a brindar un mayor empoderamiento a la mujer emprendedora" (INEGI, 2010, citado en Garduño, 2012: 2).

A estos datos habría que adherir las consideraciones del Instituto Nacional de Estadística, Geografía e Informática (INEGI) para el año 2013, el cual identifica a la mujer dentro de un 51\% del total de la población en la que el $43.5 \%$ de las mimas se encuentran por encima de los 14 años de edad y participando en la población económicamente activa, mientras que el 25\% de los hogares son liderados por mujeres como jefas de familia.

Estos datos aunados con la participación de un 33\% de la mujer en los indicadores del Producto Interno Bruto (PIB) frente a los 67\% del género masculino, lo que se refleja como una tendencia en aumento para los últimos años , teniendo en cuenta que en 1970 la participación del género femenino se daba en tan solo un $17 \%$ de la ocupación laboral en el mercado mexicano, sin considerar las iniciativas de auto-empleo y negocios informales (Bigurra, 2015).

Estas premisas están apoyando a la disminución de las barreras ideológicas en materia de equidad de género y permiten un equilibrio entre los indicadores económicos de la mujer como partícipe en el desarrollo y crecimiento económico logrando una mayor homeostasis frente al género masculino.

La mujer emprendedora en México según los datos de INEGI (2013) representa el $16 \%$ en el sector empresarial, siendo así que se encuentra regularmente en la posesión de empresas de tipología micro.

La Asociación Mexicana de Mujeres Emprendedoras (AMMJE) estima que el $60 \%$ de sus miembros representan la gestión de micro empresas, mientras que un $30 \%$ a pequeñas empresas y sólo un $7 \%$ a medianas y $3 \%$ a grandes empresas, lo que delimita a las emprendedoras como las pioneras en el fortalecimiento de los sectores MIPyME en este país.

El papel de las instituciones en el estímulo del empoderamiento de la mujer es una situación innegable para el país, pues la inversión de las utilidades por parte de las mujeres tenderá a tener una mayor centralización en el consumo y el ahorro (PROMEXICO, 2014). De la misma manera, según datos de INEGI (2013), el 47\% de las mujeres tiene sus motivaciones de ingresos alrededor del gasto familiar y la posibilidad de la obtención de mejores fuentes de oportunidad para compartir socialmente.

Asimismo, se debe tener en cuenta los estudios realizados por el Banco Interamericano de Desarrollo (2012) y citados por Garduño (2015), los cuales indican que la mujer emprendedora basará sus intenciones emprendedoras en las oportunidades, por encima de la necesidad, determinado que el 85\% de las mujeres emprendedoras en América Latina (incluyendo México) buscarán a manera de ambición el continuar con el crecimiento y sustentabilidad de sus negocios; escenario que es requerido para la efectividad en el manejo de negocios. 


\section{Conclusiones}

El empoderamiento de la mujer emprendedora es una condición que se ha reflejado en aumento tanto a nivel mundial como en los países de estudio en donde, se denotan cada vez con mayor apego, estrategias políticas y sociales que dan una importancia y legado al papel de la mujer como prioritaria en características económicas, culturales y sociales, esto visualizado en su faceta como empresaria y figura clave en los tejidos productivos y sociales de las regiones del planeta.

Al analizar las hipótesis planteadas y la interrogante que demarca el presente artículo, se puede observar que los aspectos sociales y psicológicos alrededor del perfil de la mujer emprendedora son significativos para efectos de las implicaciones económicas y culturales que este grupo poblacional tiene en el planeta, en donde China y México han sido beneficiados con la evolución ideológica de sus sectores demográficos ,y con ello, logrado de manera paulatina un empoderamiento de la mujer y un equilibrio en materia de la igualdad de género.

A pesar de que se han logrado esfuerzos significativos por lograr equidad de género dentro de las particularidades del emprendimiento empresarial y la adecuada adhesión de la mujer en la economía a través de las iniciativas emprendedoras, las condiciones que se demarcan en México y China aún representan un camino adverso en la destitución de prejuicios culturales y de estructura para una totalidad igualitaria en el campo de oportunidades gerenciales y de éxito en los negocios (Yu, 2011).

La aseveración hipotética podría refutarse de manera parcial, al identificar de acuerdo a los planteamientos analizados como en México se tienen factores evolutivos de igualdad de género, sobre todo, visto desde la variable de trabajo primordial que es el emprendimiento empresarial. A su vez, China ha tenido un avance en esta área de manera significativa teniendo buenos indicadores globales de desempeño en la adherencia de la mujer dentro de las iniciativas empresariales y su papel como empresaria (aunque en términos de los indicadores globales México sobresale en las tasas de efectividad en el manejo de esta variable), en donde, se confirma que las condiciones de desigualdad son más marcadas en China. No obstante, se puede verificar que en ambas naciones existen aún limitantes bien trazadas y que presuponen retos rigurosos para lograr un equilibrio de igualdad de género que permita una mayor participación de la mujer en la economía global ante un mundo contemporáneo que exige de las mismas oportunidades para ambos géneros.

El papel de las instituciones en la promoción de la corriente emprendedora es vital dentro del trabajo colegiado entre gobierno, sociedad y empresa, por lo que la institución de políticas públicas que incentiven el empoderamiento, un reflejo de ello es lo presentado por México que se ha dado a la tarea de potencializar el rol de la mujer en la economía y estimulado su mayor participación en las metas micro y macroeconómicas dentro de su territorio geográfico.

La apertura total o entrada de la mujer emprendedora hacia las nuevas alternativas de desarrollo en los mercados es una característica que ha sufrido cambios, sin embargo, aún se visualiza un camino reacio hacia las mismas en países en los que culturalmente existe aún un arraigo de control y democracia manejado por el género masculino, convirtiéndose así, en uno de los retos sociales y culturales que se debe disminuir mediante la articulación de los objetivos internacionales y agendas mundiales que busquen una mayor vinculación de la mujer en las metas específicas de fortalecimiento de los sectores económicos, políticos y sociales a nivel global. 


\section{Referencias}

- Asia Pacific Economic Cooperation. (Abril de 2016). APEC. Obtenido de http://www.apec.org/

- Bruin, A., Brush, C. y Welter, F. (Septiembre de 2006). Introduction to the Special Issue: Towards Building Cumulative Knowledge on Women's Entrepreneurship. Entrepreneurship, Theory and Practice, 30(5), 585-593.

- Bruton, G., Ahlstrom, D. y Obloj, K. (2007). Entrepreneurship in Emerging Economies: Where Are We Today and Where Should the Research Go in the Future. Entrepreneurship Theory and Practice, 1-14.

- Chu, P. (2000). The characteristics of Chinese Female Entrepreneurs: Motivation and personality. Journal of Enterpresing Culture, 8(1), 67-84.

- Diochon, M. (2004). Entrepreneurship and Community Economic Development. Quebec: McGill-Queen's.

- Fairlie, R., \& Woodroof, C. (2007). Mexican Entrepreneurship: A Comparison of Self-Employment in Mexico and the United States. National Bureau of Economic Research, 1-37.

- Fuentes, F., y Sánchez, S. (2010). Análisis del perfil emprendedor: una perspectiva de género. Estudios de Economía aplicada, 28(3), 1-28.

- García, F. y Marco, B. (1999). La creación de nuevas empresas como motor generador de riqueza y bienestar económico: factores de éxito y fracaso. Burgos: IX Congreso Nacional ACEDE.

- Garduño, R. (2012). Factors that influence Women's Economic Participation in México. Aguascalientes: CIDE.

- Halladay, J. y Thomas, A. (2002). The Rise of Women Entrepreneurs: People, Processes, and Global Trends. United States of America: Greenwood Publishing Group.

- Hekerson, M., y Sanandaji, T. (2011). The interaction of entrepreneurship and institutions. Journal of institutional Economics, 7(1), 47-75.

- Hendrishke, H. y Li, W. (2012). Institutional Entrepreneurship and Female Empowerment: Women Entrepreneurs in China. Sydney: China business group working paper series.

- Honing, B. (1998). What determines success? Examining the human, financial, and social capital of microentrepreneurs. Journal of business Venturing(13), 371-394.

- Jones, G., y Wadhwani, D. (2006). Entrepreneurship and Business History: Renewing the research agenda. Harvard Business School.

- Kitching, B. y Woldie, A. (2004). Female Entrepreneurs in Transitional Economies: a comparative study of Businesswomen in Nigeria and China. Honolulu, Hawaii: In Proceedings Hawaii International Conference on Business,.

- Mendieta Díaz, D. y Anaya Ortega, J. (2009). Cultura emprendedora en México: La punta de lanza para que México sea una nación más competitiva y desarrollada. México: Universidad Autónoma del Estado de México.

- Minitti, M. y Arenius, P. (2003). Women in entrepreneurship. Vienna: The Entrepreneurial Advantage Of Nations: First Annual Global Entrepreneurship Symposium .

- Observatorio Nacional del Emprendedor. (2016). ONE. Obtenido de http://www.one.inadem.gob.mx/ index. php?option $=$ com contentEview $=$ articlefid $=101$

- OCDE. (2014). Enhancing Women's Economic Empowerment through Entrepreneurship and Business Leadership in OECD Countries. Shanghai: OCDE.

- People's Republic of China State Council. (2016). Multiple measures to cut costs for real economy enterprises. Shanghai: People's Republic of China State Council.

- Perez Hernandez, P., Oliver Espinoza, R., Merrit Tapia, H., Marquez, A. y León Acevedo, J. (2006). El emprendedor en México: Ingenio vs Innovación. Madrid: CICTSI.

- Plant, R. (2009). A comparative study of motivation and entrepreneurial intentionality: Chinese and american perspectives. Journal of developmental entrepreneurship, 15(2), 187-204.

- Sánchez, J. (2008). Aprendizaje social e intenciones emprendedoras: un estudio comparativo entre México España y Portugal. Salamanca: Revista Latinoamericana de Psicología.

- Sverian, V. y Nedelea, A. (2014). Entrepreneurship, Support Of The Economic Changes In China. The USV Annals of Economics and Public Administration, 14(2), 15-28.

- Tambunan, T. (2009). Women entrepreneurship in Asian developing countries: Their development and main constraints. Journal of Development and Agricultural Economics, 1(2), 27-40.

- UNDP. (2004). Unleashing Entrepreneurship: Making Business Work for the Poor. Viena: UNDP.

- Weeks, J. y Seiler, D. (2001). Women's Entrepreneurship in Latin America: An Exploration of Current Knowledge. Washington: Inter-American Development Bank.

- Wei, S. y Zhang, X. (2011). Sex Ratios, Entrepreneurship, And Economic Growth In The People's Republic Of China. National Bureau Of Economic Research, 1-46.

- Wong, P. (2011). Academic Entrepreneurship in Asia: The Role and Impact of Universities in National Innovation Systems. Cheltenham: Edward Elgar Publishing.

- Yu, E. (Abril de 2011). Are Women Entrepreneurs More Likely to Share Power than Men Entrepreneurs in Decision-Making? International Journal of Business and Management, 6(4), 111-119. 